\title{
Immobilization of lipase B within micron-sized poly- $N$-isopropylacrylamide hydrogel particles by solvent exchange $\dagger$
}

\author{
Kornelia Gawlitza, ${ }^{a}$ Changzhu Wu ${ }^{b}$ Radostina Georgieva, ${ }^{c d}$ Dayang Wang, $\ddagger^{e}$ \\ Marion B. Ansorge-Schumacher ${ }^{b}$ and Regine von Klitzing*a
}

Received 28th February 2012, Accepted 2nd May 2012

DOI: $10.1039 / \mathrm{c} 2 \mathrm{cp} 40624 \mathrm{a}$

The aim of the present work is the use of a water soluble enzyme in an organic solvent, still with a pronounced catalytic activity. Therefore, lipase B from Candida antarctica (CalB) is immobilized within micron-sized thermosensitive p-NIPAM hydrogel particles using a solvent exchange from polar to organic solvents. The absorbed amount of CalB is investigated at different immobilization temperatures. Confocal laser scanning microscopy (CLSM) shows that CalB is homogeneously distributed within the polymer network. An enhanced specific activity of CalB in $n$-hexane is achieved after immobilization within the p-NIPAM microgels. In order to get information on the supply of the substrate depending on the temperature, the activity is determined at different reaction temperatures. Additionally, the system is stable in the organic solvent, namely $n$-hexane, and shows a good reusability.

\section{Introduction}

In the last decades, the technical application of enzymes has been developed tremendously, leading to a strong competition between biocatalysts and chemical catalysts. Beside the mild conditions during reactions, one of the most important advantages of biocatalysts is their high chemo-, stereo- and regioselectivity. ${ }^{1,2}$ Enzymes are able to produce chiral building blocks with an enantiomeric purity of $\geq 99 \%$ which is of great importance for the production of pharmaceuticals. For the application in industrial processes it is necessary that the used enzymes are stable at high temperatures, at different $\mathrm{pH}$ values and in the presence of organic solvents. To achieve this stability many methods have been developed, among them immobilization. Since immobilization also improves the handling of the catalysts during synthesis, it has grown into an important and challenging research field. By definition, the methods are divided

${ }^{a}$ Technische Universität Berlin, Stranski-Laboratory for Physical and Theoretical Chemistry, Institute of Chemistry, 10623 Berlin, Germany.E-mail: klitzing@chem.tu-berlin.de

${ }^{b}$ Technische Universität Berlin, Department of Enzyme Technology, Institute of Chemistry, 10623, Berlin, Germany

${ }^{c}$ Charité-Universitätsmedizin Berlin, Institute of Transfusion

Medicine, Center for Tumor Medicine, 10117 Berlin, Germany

${ }^{d}$ Trakia University Stara Zagora, Medical Faculty, Department of Medical Physics, Biophysics and Radiology, 6000 Stara Zagora, Bulgaria

${ }^{e}$ Max Planck Institute of Colloids and Interfaces, D-14424, Potsdam, Germany

$\dagger$ Electronic supplementary information (ESI) available. See DOI: $10.1039 / \mathrm{c} 2 \mathrm{cp} 40624 \mathrm{a}$

$\ddagger$ Present address: University of South Australia, Ian Wark Research Institute, SA 5095, Adelaide, Australia. into two main categories. The first one is the immobilization by attachment where either macroscopic insoluble aggregates are formed by linking the biocatalysts to each other (carrier-less crosslinking) or by binding them to the surface of an organic or inorganic support (adsorption onto a carrier, covalent binding to a carrier). The second category is entrapment which involves encapsulation in semi-permeable membranes and embedding into a matrix. Due to the reduced contact to the carrier compared to the immobilization by attachment, the residual mobility and flexibility of the biocatalysts are much higher. ${ }^{3}$ Embedding within polymer matrices is of particular interest due to the wide field of applications for polymer particles.

In a former study the enzyme CalB and inorganic hydrophilic CdTe quantum dots were immobilized within agarose microgel particles by exchanging a polar solvent (water) against an organic one (isopropanol or $n$-hexane). The activity of CalB increased after encapsulation within the polymer matrix. ${ }^{4}$ In contrast to agarose, microgel particles made of poly- $N$-isopropylacrylamide (p-NIPAM) show a low polydispersity and a pronounced response to external stimuli. This makes them really useful for applications like drug delivery ${ }^{5,6}$ or as biosensors ${ }^{7}$ and enzyme supports. ${ }^{8,9}$ The crosslinked p-NIPAM network can be synthesized by surfactant free emulsion polymerization, ${ }^{10,11}$ forming a thermoresponsive polymer. Due to the lower critical solution temperature (LCST) of the linear polymer segments made of $N$-isopropylacrylamide (NIPAM) the formed microgel network shows a volume phase transition at around $32{ }^{\circ} \mathrm{C} .{ }^{12}$ This can be used to control the immobilized amount of enzymes within p-NIPAM hydrogel particles on one hand and the supply of substrates after immobilization of enzymes on the other hand. By integrating different comonomers into the polymer network, 
the volume phase transition temperature (VPTT) of the p-NIPAM microgel particles can be adjusted at a defined value. ${ }^{13-15}$

In the early 1990s the adsorption of proteins onto p-NIPAM microgels was studied intensively. ${ }^{16,17}$ From these studies it is not clear if the immobilized enzyme is located inside the polymer network or at the surface. Additionally, in most cases the activity of enzymes like catalase and $\beta$-glucosidase decreased after immobilization within or onto microgel matrices. ${ }^{18}$ This decrease is probably caused by structural changes in the enzyme introduced during the immobilization procedure or by a lower accessibility of the substrate to the active site of the immobilized enzyme. ${ }^{19}$ Further studies demonstrated that enzymes can be immobilized within p-NIPAM microgel particles with a diameter between $60 \mu \mathrm{m}$ and $80 \mu \mathrm{m}$. The location of the enzyme inside the polymer network was elucidated by using confocal laser scanning microscopy (CLSM) ${ }^{20,21}$ To benefit from the low polydispersity and the high surface-to-volume ratio, it is more efficient to use smaller p-NIPAM particles. Welsch et al. reached an enhanced activity of $\beta$-D-glucosidase after its immobilization within core-shell particles, where the core consisted of polystyrene and the shell consisted of p-NIPAM. ${ }^{22}$ Due to the small size of the p-NIPAM particles it could not be proven whether the enzyme is really immobilized within the polymer network. All described studies for enzyme immobilization within p-NIPAM microgel particles have been performed in water. Despite the fact that many substrates are rather soluble in organic solvents, many enzymes are soluble in water. The challenge is to design an efficient system, where both compounds are in their suitable environment. An example is water-soluble lipase which cleaves lipids. The latter are soluble in organic solvents. One strategy to solve this problem is to bring the lipase into a hydrophobic matrix which can be dispersed in the organic phase and which is permeable for the substrate.

The usage of organic solvents in enzyme-catalysed reactions is important for industrial applications to increase the solubility of organic substrates and therefore to improve the formation of the products. $^{23-25}$ In the present paper, the immobilization of CalB within p-NIPAM microgel particles was studied by changing water, as the solvent, with the organic solvents, isopropanol and $n$-hexane. Furthermore, the p-NIPAM polymer particles show a thermosensitive behaviour which can be used to control the uptake of the enzyme. The immoblized amount of enzyme at different temperatures, the enzyme distribution within the polymer particles, the activity at different reaction temperatures and the reusability of the system applying CLSM and gas chromatography were investigated. In the literature, the usage of immobilized systems in organic solvents was either shown for macrogels with no enhanced specific activity ${ }^{26-28}$ or for reversed micelles where the location of the enzyme was not invetsigated. ${ }^{29}$ In the present paper the location of the enzyme CalB was determined and an enhanced activity in organic solvents is reached.

\section{Experimental}

\subsection{Materials}

$N$-Isopropylacrylamide $(97 \%) \quad$ (NIPAM), octanoic acid ( $\geq 99 \%$ ), 1-octanol ( $\geq 99 \%$ ), bovine serum albumin standard (BSA, $2 \mathrm{mg} \mathrm{mL}^{-1}$ ) and Bradford Reagent were purchased from Sigma-Aldrich (Munich, Germany). Fluorescein-5-isothiocyanate
(FITC) was from Merck (Darmstadt, Germany) and $N, N^{\prime}$-methylenebis(acrylamide) (MBA) ( $\geq 99.5 \%$ ) and potassium peroxodisulfate (KPS) $(\geq 99 \%)$ were from Fluka (Munich, Germany). Lipase B from Candida antarctica (CalB) was generously donated by Novozymes A/S (Bagsvaerd, Denmark). NIPAM was purified by recrystallization in $n$-hexane. Other chemicals were used as received. Water was taken from a three-stage Millipore Milli-Q Plus 185 purification system.

\subsection{Preparation techniques}

2.2.1 Synthesis of large p-NIPAM microgel particles. To localize the microgel particles after immobilization by CLSM, micron-sized p-NIPAM microgel particles with a crosslinker content of $0.25 \%$ were synthesized by surfactant free emulsion polymerization via a temperature ramp according to Meng et $a l .{ }^{30}$ Therefore, $1.8 \mathrm{~g}$ of the monomer NIPAM $(0.015 \mathrm{~mol})$ and $8 \mathrm{mg}$ of the crosslinker MBA $\left(5 \times 10^{-5} \mathrm{~mol}\right)$ were dissolved in $125 \mathrm{~mL}$ water. The solution was degassed for $1 \mathrm{~h}$ at $45^{\circ} \mathrm{C}$. Afterwards, a solution of $1 \mathrm{~mL}$ KPS $(0.08 \mathrm{M})$ was added to the mixture while stirring continously. The temperature was slowly increased to $65{ }^{\circ} \mathrm{C}$ at a rate of $1{ }^{\circ} \mathrm{C}$ every 2 minutes. Finally, the polymerization was completed by stirring overnight at $65^{\circ} \mathrm{C}$ under a $\mathrm{N}_{2}$ atmosphere. The received microgel particles were purified by filtering over glass wool, dialysis for 2 weeks and finally freeze drying at $-85^{\circ} \mathrm{C}$ under $1 \times 10^{-3}$ bar for $48 \mathrm{~h}$.

2.2.2 Immobilization of CalB within p-NIPAM microspheres. For the immobilization of the enzyme, p-NIPAM particles $(5 \mathrm{mg})$ and CalB $(0.1 \mathrm{~mL})$ were dissolved in buffer (0.1 M potassium phosphate buffer, $\mathrm{pH}$ 7), stirred overnight and centrifuged for $15 \mathrm{~min}$ at $9000 \mathrm{~g}$. The residue was redispersed in the water miscible solvent, isopropanol, and washed three times. Finally, another solvent exchange was performed by the exchange of isopropanol against the water immiscible solvent, $n$-hexane. The immobilization experiment was done at $25^{\circ} \mathrm{C}$ and $50{ }^{\circ} \mathrm{C}$ during the whole immobilization procedure. Furthermore, CalB and p-NIPAM microgel particles were mixed at $25^{\circ} \mathrm{C}$, stirred for 30 minutes followed by heating the mixture to $50{ }^{\circ} \mathrm{C}$ for the immobilization overnight. Native CalB was treated the same way for all temperature procedures. For the determination of the location of CalB within or at the surface of the p-NIPAM particles, CalB was labeled with FITC according to the literature. ${ }^{31}$ The residue after the first centrifugation was redispersed in buffer and isopropanol, respectively.

\subsection{Characterization methods}

2.3.1 Light scattering. The size of the microgel particles was determined by DLS. Using an ALV goniometer setup with a Nd:YAG laser as the light source $(\lambda=532 \mathrm{~nm})$ correlation functions were recorded at a constant scattering angle of $60^{\circ}$. The correlation functions were generated using an ALV-5000/E multiple- $\tau$ digital correlator and subsequently analyzed by inverse Laplace transformation (CONTIN). ${ }^{32}$

Static light scattering data were recorded at scattering angles from $17^{\circ}$ to $37^{\circ}$ with $2^{\circ}$ steps in between using an ALV/CGS-3 compact goniometer system equipped with an ALV/LSE-5004 correlator to determine the molecular weight of the polymer particles. The concentration of the polymer particles was varied 
from $1 \times 10^{-6} \mathrm{~g} / \mathrm{g}$ to $9 \times 10^{-6} \mathrm{~g} / \mathrm{g}$. The measurements were done at $25^{\circ} \mathrm{C}$ using a Huber Compatible Control thermostat. A He-Ne laser $(\lambda=632.8 \mathrm{~nm})$ was used and the laser light was polarized vertically with respect to the instrument table.

2.3.2 Confocal laser scanning microscopy. The location of CalB after immobilization within the microspheres was investigated by confocal laser scanning microscopy (CLSM). Therefore, the samples were redispersed in buffer or in isopropanol. For microscopy, from each preparation a drop of roughly 201 was placed on a cover slip and investigated using an inverted microscope Axiovert $200 \mathrm{M}$ equipped with a $100 \times$ oil immersion objective (numerical aperture 1.3) and a Zeiss LSM 510Meta confocal scanning unit (Zeiss MicroImaging $\mathrm{GmbH}$, Jena, Germany). The fluorescence images were prepared using the $488 \mathrm{~nm}$ line of the argon laser for excitation and a $505 \mathrm{~nm}$ long-pass emission filter. Z-stacks were performed with a step of $50 \mathrm{~nm}$ upwards starting at the surface of the cover slips. Different Z-stacks of the samples were analyzed using the LSM 510 software and displayed as an overlay of transmission and fluorescence channels in orthogonal section views.

2.3.3 Atomic force microscopy. The Atomic Force Microscopy (AFM) images were measured using a nanoscope III controller on a multimode microscope working in tapping mode.

2.3.4 Determination of the immobilized amount of CalB. The amount of CalB which is immobilized within the p-NIPAM microgel particles was achieved via determination of the total protein content in solution using the Bradford reagent according to the manufacturer's instruction and assuming that CalB was the only protein present in the commercial preparation (ESI $\dagger$ ). UV-VIS spectra were measured with the PerkinElmer Lambda 25 UV-VIS-spectrometer.

2.3.5 Determination of the catalytic activity. The catalytic performance of CalB was determined via the esterification of 1 -octanol and octanoic acid in $n$-hexane. Typically, $50 \mu \mathrm{L}$ droplets of the aqueous solution of native CalB or $5 \mathrm{mg}$ of p-NIPAM particles loaded with CalB were given to $1.0 \mathrm{~mL}$ of substrate solution in $n$-hexane containing $100 \mathrm{mM}$ 1-octanol and $100 \mathrm{mM}$ octanoic acid. These dispersions were shaken at $25{ }^{\circ} \mathrm{C}, 32{ }^{\circ} \mathrm{C}$ or $50{ }^{\circ} \mathrm{C}$ for $15 \mathrm{~min}$. The supernatant of the immobilized CalB or the upper part of the solution with native CalB was investigated with a gas chromatograph to determine the activity of CalB. Every $5 \mathrm{~min} 150 \mu \mathrm{L}$ of solution were withdrawn and analyzed for ester concentration via gas chromatography (Shimadzu 2010; BPX5 column from SGE: length $25 \mathrm{~m}$, ID $0.22 \mathrm{~mm}$; film thickness: $0.25 \mathrm{~m}$; detector: FID at $300{ }^{\circ} \mathrm{C}$; injector: $275.0{ }^{\circ} \mathrm{C}$, injection volume of $1 \mu \mathrm{L}$, split model; temperature program: start temperature $80.0^{\circ} \mathrm{C}$, hold for $0.5 \mathrm{~min}$, temperature rise $20{ }^{\circ} \mathrm{C} \mathrm{min}{ }^{-1}$ from $80{ }^{\circ} \mathrm{C}$ to $170{ }^{\circ} \mathrm{C}$ and $5{ }^{\circ} \mathrm{C} \mathrm{min}{ }^{-1}$ rise from $170{ }^{\circ} \mathrm{C}$ to end temperature $\left.200{ }^{\circ} \mathrm{C}\right){ }^{4}$ The concentration of the product, octyl octanoate, was calculated from the peak area at a typical retention time of $10 \mathrm{~min}$. All reactions were performed in triplicate. To investigate the stability of the system, some samples of immobilized CalB were stored in $n$-hexane and after different time intervals the samples were used as catalyst for the esterification reaction. The reusability of the system was investigated by testing the activity of one sample followed by testing the same sample again after centrifugation and washing. This procedure was repeated four times.

\section{Results and discussion}

Surfactant free emulsion polymerization using a temperature ramp was applied in order to obtain large p-NIPAM particles. ${ }^{30}$ To investigate the size and the swelling behaviour of the synthesized microgel particles measurements by means of DLS were recorded. The swelling curves for the microgel particles in water and isopropanol are presented in Fig. 1. The hydrodynamic diameter $\left(D_{\mathrm{h}}\right)$ was determined by cumulant anlalysis of the correlation functions. Fig. S4 (ESI $\dagger$ ) shows one correlation function of the microgel particles in water at $24{ }^{\circ} \mathrm{C}$ leading to a $D_{\mathrm{h}}$ of $1.80 \mu \mathrm{m}$ and a polydispersity index (PDI) of 0.076. This PDI shows the monodispersity of the synthesized polymer particles. An increase in temperature to $40{ }^{\circ} \mathrm{C}$ leads to a decreased $D_{\mathrm{h}}$ of $0.21 \mu \mathrm{m}$. The swelling curve in water shows a decreased VPTT at around $28^{\circ} \mathrm{C}$ compared to p-NIPAM microgel particles which are synthesized without temperature ramp. ${ }^{12}$ Meng et al. synthesized p-NIPAM microgel particles with acrylic acid as comonomer using the temperature ramp leading to a VPTT of around $31{ }^{\circ} \mathrm{C} .{ }^{30}$ As known from the literature, the VPTT of p-NIPAM with acrylic acid as comonomer is higher than that of pure p-NIPAM particles. ${ }^{33}$ The decreased VPTT of the particles synthesized in the presented work are in good agreement with this investigation. Dissolving the polymer particles in isopropanol leads to a $D_{\mathrm{h}}$ of $1.16 \mu \mathrm{m}$. The swelling curve of the synthesized microgel particles in isopropanol shows a steep decrease of the hydrodynamic diameter to $0.07 \mu \mathrm{m}$ at $40{ }^{\circ} \mathrm{C}$. Due to the fact that the swelling curve shows a decrease in size and a reduced LCST water is a better solvent than isopropanol. A comparison of the microgel particles in water and isopropanol at $24{ }^{\circ} \mathrm{C}$ leads to a decrease in diameter of $0.64 \mu \mathrm{m}$ in isopropanol due to the more hydrophobic solvent compared to water. Atomic Force Microscopy (AFM) was also used to investigate the shape and the monodispersity of the sample. Fig. S5 (ESI $\dagger$ ) shows spherical microgel particles. The ordered structure on the surface suggests that the p-NIPAM microgel particles are monodisperse which is in good agreement with the results from DLS measurements. The determined particle sizes allow the application of CLSM for visualization of the p-NIPAM microgel particles giving the opportunity to observe the distribution of fluorescently labeled enzyme inside them. After incubation of the hydrogel particles with FITClabeled CalB the solution was centrifuged and the p-NIPAM particles were redispersed either in isopropanol or in buffer.

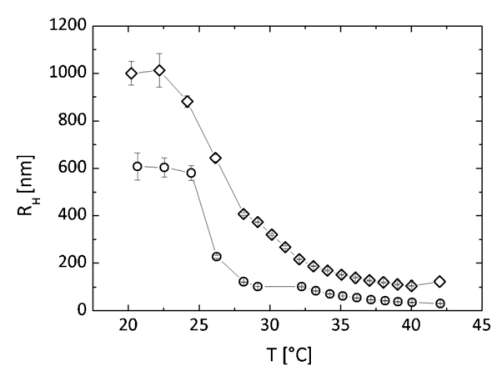

Fig. 1 Swelling curve for p-NIPAM in isopropanol (circles) and in water (rhombs). 


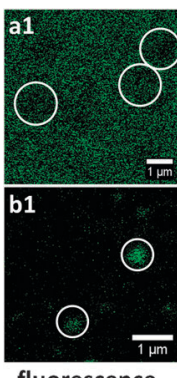

fluorescence

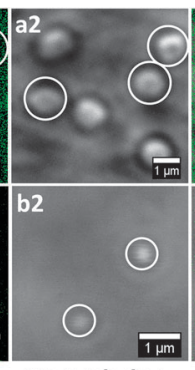

transmission

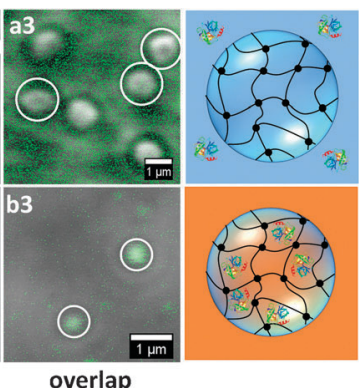

Fig. 2 CLSM-images of the residue after incubation with CalB redispersed in buffer (a) and isopropanol (b) in fluorescence mode, transmission mode and as a super imposed image of both. The gradient of the crosslinker in the polymer structure is simplified in the sketch for the sake of clarity.

Fig. 2 shows CLSM micrographs of the samples. Images a1 and $b 1$ give the fluorescence of the sample and images a 2 and b2 reflect the transmission of the sample. Images a3 and b3 display an overlap of the fluorescence and transmission mode which proves whether the fluorescent areas match with the position of the p-NIPAM microgel particles. The upper series of CLSM-images show the residue after enzyme immobilization and centrifugation redispersed in buffer. Obviously, the fluorescence is distributed over the whole scan area but there also exist some areas with less fluorescence (white circles). These areas fit to the position of the microgel particles shown in the overlap of the first two images. Hence, the labeled enzyme is not located within the p-NIPAM particles but outside the particles. The lower series of Fig. 2 shows the hydrogel particles after redispersion in isopropanol. It can be seen that the measured fluorescence is mainly concentrated at two positions (white circles). The overlap of the fluorescence and the transmission images shows that these fluorescence spots are exactly at the position of the microgel particles which leads to the conclusion that CalB is located within or on the surface of the p-NIPAM particles after solvent exchange.

In order to get information about the distribution of the enzymes the microgels redispersed in isopropanol were investigated in more detail using the z-stack option of the CLSM. Therefore, the sample was scanned in 18 different $x$-y-planes with a distance of $50 \mathrm{~nm}$ in the $z$-direction between them. Fig. 3a displays an orthogonal section view of these slices. In the center one of the $x-y$-planes framed by a blue box is shown. The upper green box frames the $x-z$-plane of a cut through the sample along the green horizontal line in the central $x-y$-image. The right hand red framed box represents the $y-z$-plane of the cut along the red vertical line. The blue line in the $x-z$ and $y-z$ images represents the $z$-position of the $x-y$-plane displayed in the center. Due to the fact that all three planes show a spherically shaped fluorescent object, it can be concluded that CalB is located inside the particles and not only at the surface. The distribution of the enzyme between particles and solvent was further observed by CLSM after drying. The sample was dried directly under the microscope and immediately scanned in $23 x$-y-planes with $50 \mathrm{~nm}$ distance in the $z$-direction. The orthogonal section view of the z-stack is shown in Fig. 4. The $y-z$ - and $x-z$-planes show no more spherical fluorescence images of the particles. Obviously, the labeled enzyme is now
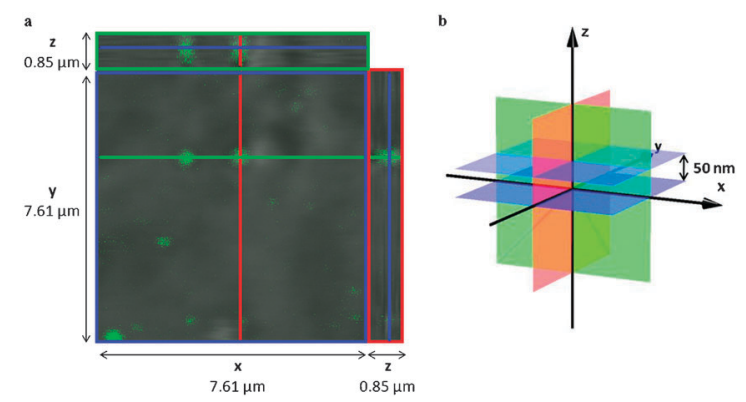

Fig. 3 Orthogonal section view of one $x-y$-plane of p-NIPAM particles with immobilized CalB after redispersion in isopropanol (a) and schematic explanation of the blue, red and green box (b).

located outside the polymer network, on top of the dried particles and on the glass surface. This fact also proves that CLSM is an adequate method to observe the localization of enzymes. Probably, the evaporation of the solvent, which is assumed to start at the hydrogel surface, creates a negative pressure (capillary forces) within the hydrogel particles leading to emersion of the enzyme molecules. The release of enzymes by the drying process is an interesting effect which can be used for regeneration of the polymer matrix and reuse by immobilization of new enzymes.

The immobilization of the enzyme within the p-NIPAM microgel particles by solvent exchange can be explained by the high affinity of CalB to aqueous environment. If the residue is dissolved in buffer, the enzyme can diffuse out of the p-NIPAM microgel particles and mainly stays in the buffer. The exchange of water against isopropanol leads to a decrease of $D_{\mathrm{h}}$ of the p-NIPAM microgel particles from $1.56 \mu \mathrm{m}$ to $0.94 \mu \mathrm{m}$ at $25^{\circ} \mathrm{C}$. Simultaneously, a residual amount of water remains inside the microgel particles and presents a kind of "aqueous cage" for the enzymes. Due to the lower solubility of CalB in isopropanol the enzyme is pressed into the polymer network of p-NIPAM microgels.

In order to profit from the thermoresponsibility of p-NIPAM particles, the immobilization procedure was additionally done (1) at $50{ }^{\circ} \mathrm{C}$ before and during the immobilization process and (2) by heating to $50{ }^{\circ} \mathrm{C}$ after mixing of CalB and the p-NIPAM microgel particles. The schematic process for the immobilization at different temperatures is shown in Fig. 5 and 6.

To calculate the amount of CalB immobilized within p-NIPAM particles the molecular weight of the polymer particles was determined by SLS. An estimated residual water content of around $10 \%{ }^{34}$ was used for calculation of the concentrations of

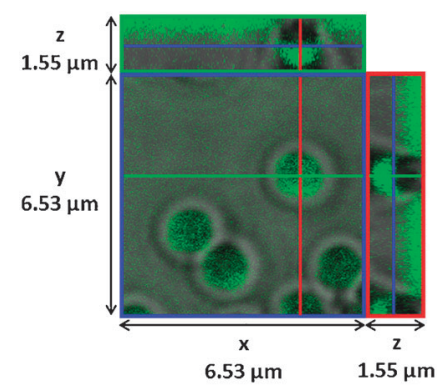

Fig. 4 Orthogonal section view of p-NIPAM particles with immobilized CalB after drying. 


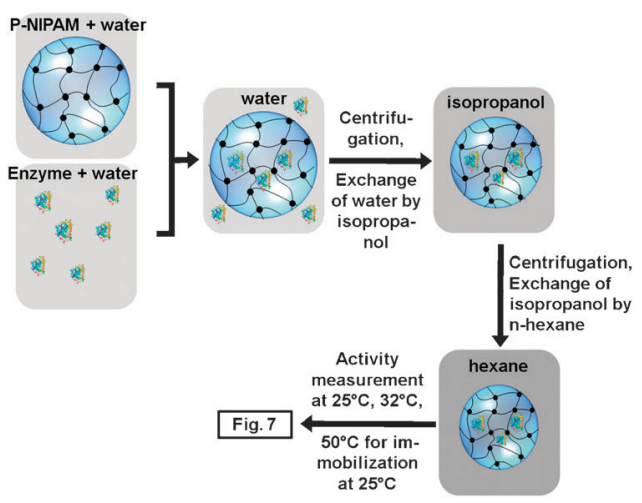

Fig. 5 Schematic process of the immobilization of CalB within p-NIPAM microgel particles at $25{ }^{\circ} \mathrm{C}$ and $50{ }^{\circ} \mathrm{C}$. Due to the fact that after immobilization at $50{ }^{\circ} \mathrm{C}$ no enzyme is adsorbed, the activity reaction was only performed for the immobilization at $25^{\circ} \mathrm{C}$. The internal structure of the polymer particles is simplified for the sake of clarity.

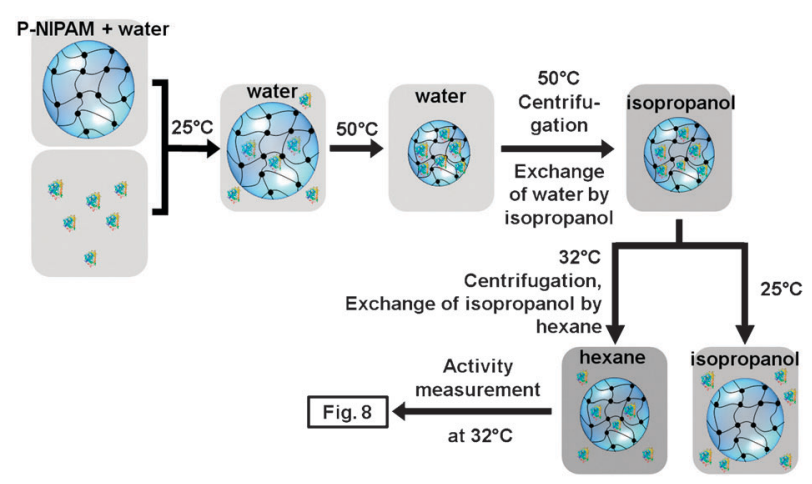

Fig. 6 Schematic process for the immobilization of CalB within p-NIPAM microgel particles by increasing the temperature to $50{ }^{\circ} \mathrm{C}$ after mixing. The internal structure of the polymer particles is simplified for the sake of clarity.

p-NIPAM microgel solutions. The received Zimm-Plot is shown in Fig. S6 $($ ESI $\dagger)$ with $\mathrm{d} n / \mathrm{d} c=0.167 \mathrm{~cm}^{3} \mathrm{~g}^{-1} \cdot 35$ The extrapolation of the angle and the concentration to 0 leads to a molecular weight $M_{\mathrm{W}}$ of $3.0 \times 10^{10} \mathrm{~g} \mathrm{~mol}^{-1}$, a second virial

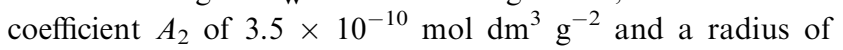
gyration $R_{\mathrm{g}}$ of $432 \mathrm{~nm}$. Using the molecular weight of p-NIPAM and CalB (33273 $\mathrm{Da}^{36}$ ) the amount of immobilized CalB within the $\mathrm{p}$-NIPAM particles for the different temperature treatments can be calculated. The results are summarized in Table 1. While an immobilization at $25{ }^{\circ} \mathrm{C}$ results in a loading of $5.4 \times 10^{3} \mathrm{CalB}$ particles per p-NIPAM particle, no enzyme is immobilized when p-NIPAM particles and CalB were mixed after increasing the temperature above the VPTT leading to collapsed polymer particles. Due to the narrower polymer network the enzyme has no possibility to diffuse into the p-NIPAM particles. In contrast, the increase of the temperature to $50{ }^{\circ} \mathrm{C}$ after mixing of enzyme and polymer particles leads to a much higher loading efficiency of $12.6 \times 10^{3} \mathrm{CalB}$ particles per polymer particle. At room temperature the enzyme diffuses through the polymer particles. The increase in temperature and the following collapse leads to enzyme entrapment within the p-NIPAM microgel network.

To investigate the reversibility of this absorption, the system was cooled down to room temperature and washed with
Table 1 Adsorbed amount of CalB within p-NIPAM particles after immobilization via solvent exchange at different temperatures

\begin{tabular}{lll}
\hline$T$ in ${ }^{\circ} \mathrm{C}$ & $\begin{array}{l}m_{\text {CalB }} / \mu g \text { per mg } \\
\text { p-NIPAM }\end{array}$ & $\begin{array}{l}N_{\text {CalB }} \text { per } \\
\text { p-NIPAM }\end{array}$ \\
\hline 25 & 6 & $5.4 \times 10^{3}$ \\
50 & 0 & 0 \\
50 (after mixing) & 14 & $12.6 \times 10^{3}$ \\
\hline
\end{tabular}

isopropanol again. Afterwards, no more enzyme was left within the p-NIPAM particles, which indicates that CalB diffuses out of the system in isopropanol by decreasing the temperature. The collapse of the system at $50{ }^{\circ} \mathrm{C}$ makes the p-NIPAM microgel particles more hydrophobic. Therefore, water is pressed out of the polymer network while CalB remains inside. By the exchange of water against hot isopropanol the rest amount of water within the microgels is replaced by the more hydrophobic isopropanol. The enzyme is not able to diffuse out of the polymer system due to its size. By cooling the system down to room temperature afterwards, the p-NIPAM microgel particles swell leading to a larger mesh size and an emersion of CalB. Therefore, no adsorbed amount of CalB is determined within p-NIPAM. The dimensions of CalB are supposed to be $3 \mathrm{~nm} \times$ $4 \mathrm{~nm} \times 5 \mathrm{~nm} .{ }^{36}$ Hence, the assumption can be made that the microgel particles have a mesh size below these dimensions in the collapsed state and above these dimensions in the swollen state.

For catalytic applications, it is required that the enzyme is still active after immobilization within the p-NIPAM matrix. The catalytic activity was determined using an esterification reaction of 1-octanol and octanoic acid in $n$-hexane with octyloctanoate as a product. Due to the low solubility of CalB in $n$-hexane, the specific activity of immobilized CalB is much higher than that of native CalB. To compare the activity of native and immobilized CalB, the same esterification reaction was performed in both systems. One has to take into account that CalB dissolved in a buffer solution. Therefore, CalB is still surrounded by hydration water even in $n$-hexane. The reaction was performed at $25{ }^{\circ} \mathrm{C}, 32{ }^{\circ} \mathrm{C}$ and $50{ }^{\circ} \mathrm{C}$ to investigate if the collapse of the p-NIPAM microgel particles has an influence on the possibility of the substrate to diffuse into the polymer particles and therefore to form the product by reaction with the enzyme. The specific activity for native CalB in $n$-hexane and immobilized CalB in p-NIPAM redissolved in $n$-hexane for the three temperatures is shown in Fig. 7. In this case the immobilization was done at $25{ }^{\circ} \mathrm{C}$. Accordingly, the specific activity for all three temperatures of immobilized CalB is much higher than for native CalB. This enhanced activity can be explained by the more homogeneous distribution of the immobilized enzyme in $n$-hexane. Due to the fact that CalB is added dissolved in aqueous solution a phase separation occurs after addition to $n$-hexane which leads to a macroscopic interface. The biocatalysis takes place at the enzymes which are located at this macrocopic interface. In comparison, the immobilization within p-NIPAM particles creates a much larger total internal interface at which the esterification reaction normally takes place. Another explanation can be given by the higher density of CalB within the polymer particles compared to the native $\mathrm{CalB}$ in the reaction solution. 


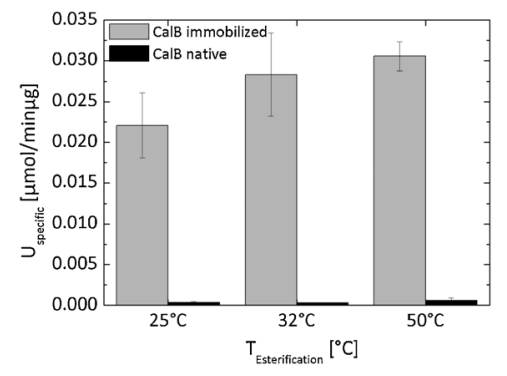

Fig. 7 Specific activity in $n$-hexane of native and immobilized CalB investigated at $25{ }^{\circ} \mathrm{C}, 32{ }^{\circ} \mathrm{C}$ and $50{ }^{\circ} \mathrm{C}$ after immobilization at $25^{\circ} \mathrm{C}$.

The diffusion of the substrate molecules into the p-NIPAM microgel particles leads to an increased collision frequency of enzyme and substrate resulting in a higher concentration of product. In addition, Fig. 7 shows that a temperature change during the esterification reaction of the immobilized system has no pronounced influence on the specific activity normalized with respect to the one of native CalB. One explanation could be that even at high temperatures the mesh sizes of p-NIPAM with a crosslinker content of $0.25 \%$ are large enough for diffusion of the substrate into the microgel particles.

The activity was also investigated for CalB which was immobilized by increasing the temperature to $50{ }^{\circ} \mathrm{C}$ after mixing with p-NIPAM microgel particles to find out if the higher amount of adsorbed enzyme leads to a higher specific activity. The activity reaction was conducted at $32{ }^{\circ} \mathrm{C}$ and the results are shown in Fig. 8. Against one's expectations, the specific activity decreases compared to the system which was immobilized at $25{ }^{\circ} \mathrm{C}$. As described before, cooling the system in isopropanol down to room temperature after immobilization leads to a complete emersion of CalB. At the reaction temperature of $32{ }^{\circ} \mathrm{C}$ the p-NIPAM microgel particles are not in a total collapsed state which can also lead to an emersion of CalB out of the p-NIPAM matrix. In this case, CalB is existent as native CalB in $n$-hexane. As shown in the presented results the specific activity for native CalB in $n$-hexane is lower than for immobilized CalB which explains the lower specific activity for the system immobilized at $50{ }^{\circ} \mathrm{C}$ after mixing of the components.

As a next step the stability in $n$-hexane and the reusability of the CalB immobilized in this promising system were

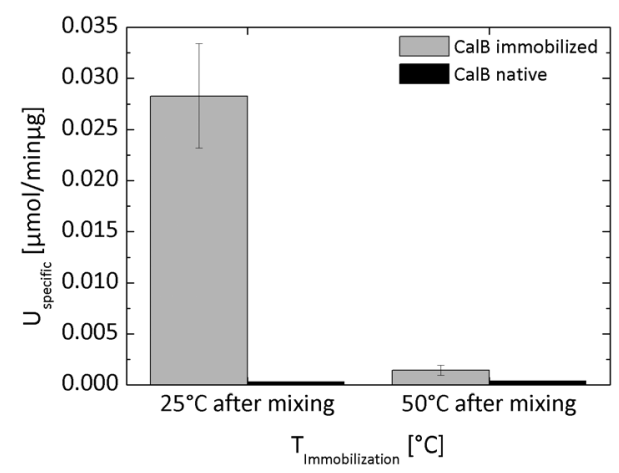

Fig. 8 Specific activity in $n$-hexane of native and immobilized CalB after immobilization at $25^{\circ} \mathrm{C}$ and $50{ }^{\circ} \mathrm{C}$ after mixing of CalB and p-NIPAM microgel particles measured at $32{ }^{\circ} \mathrm{C}$. For native $\mathrm{CalB}$ the same temperature treatment was done as for the immobilized system.
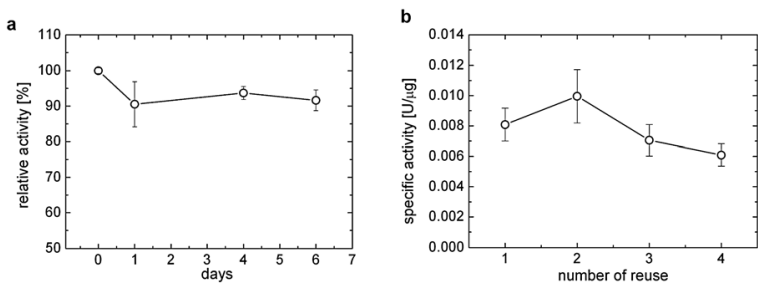

Fig. 9 Stability of immobilized CalB in $n$-hexane (a) and reusability of the system (b).

further investigated. Fig. 9a shows that the activity decreases by only $10 \%$ compared to the starting value within six days. Interestingly, this decrease is not continuous, but rather occurs at the first measuring point after starting the investigation. This implies that the activity loss is not a consequence of deactivation of the immobilized catalyst, but might result from a leaching of enzyme from the surface of p-NIPAM particles upon initial application. For catalytic applications the reusability of a system also plays an important role. Fig. 9b shows a slight increase of the specific activity after the first usage. The catalytic reaction and the washing procedure may affect a folding of the enzyme leading to a better accessibility of the active center. Additionally, it is clearly shown that the immobilized CalB can be used several times with just a slightly decreasing activity.

\section{Conclusions}

The aim of the presented work was to use water soluble enzymes also in organic solvents, since most of the substrates are soluble in organic solvents. It has been demonstrated that CalB can be immobilized within the network of p-NIPAM microgel particles via solvent exchange from polar to organic solvents. Using confocal laser scanning microscopy (CLSM) the enzyme location inside the microgel particles after changing the solvent was proved. A change of the temperature above the VPTT after mixing of the components results in a higher amount of CalB within the p-NIPAM microgel particles compared to an immobilization at $25^{\circ} \mathrm{C}$. This high amount of immobilized CalB is emersed by decreasing the temperature back to $25^{\circ} \mathrm{C}$ after immobilization. In contrast, no entrapment of the enzyme is reached by an increase in temperature above the VPTT before mixing of the compenents due to the collapsed polymer network. The achieved embedding of $\mathrm{CalB}$ at $25^{\circ} \mathrm{C}$ leads to an enhanced specific activity in $n$-hexane compared to a solution of native CalB in buffer added as a drop to $n$-hexane which is helpful for technical application. This enhanced activity can be explained by the larger total internal interface which is created when CalB is immobilized within p-NIPAM microgel particles. Furthermore, the immobilized enzyme dispersed in $n$-hexane is stable which is shown by a relative activity of $90 \%$ after 6 days. The reuse of the system 4 times results in a slight decrease of the specific activity. The advantage of embedding enzymes in hydrated polymer matrices is a more homogeneous distribution, easier accessibility and handling of the enzymes. Additionally, no chemical adjustment of the polymer matrix for the embedding is needed. By applying this solvent exchange method to other enzymes the described procedure can be a really helpful approach for creating new biocatalysts, especially for the chemical synthesis in organic solvents. 


\section{Acknowledgements}

The authors thank Helmuth Möhwald and Shuo Bai for helpful discussions and collaboration regarding the solvent exchange. This work was supported by the DFG via the Cluster of Excellence "Unifying Concepts in Catalysis". The authors also want to acknowledge Novozymes $\mathrm{A} / \mathrm{S}$ for donating CalB.

\section{References}

1 R. N. Patel, Biomol. Eng., 2001, 17, 167-182.

2 R. N. Patel, Adv. Synth. Catal., 2001, 343, 527-546.

3 M. B. Ansorge-Schumacher, Handbook of Heterogeneous Catalysis, Wiley VCH, Weinheim, vol. 1, 2008.

4 S. Bai, C. Wu, K. Gawlitza, R. von Klitzing, M. B. AnsorgeSchumacher and D. Wang, Langmuir, 2010, 26, 12980-12987.

5 G.-H. Hsiuea, S. hui Hsub, C.-C. Yangc, S.-H. Leed and I.-K. Yang, Biomaterials, 2002, 23, 457-462.

6 G. M. Eichenbaum, P. F. Kiser, A. V. Dobrynin, S. A. Simon and D. Needham, Macromolecules, 1999, 32, 4867-4878.

7 J. R. Retama, M. S.-P. López, J. H. Péreza, G. F. Cabanillasc, E. López-Cabarcosb and B. López-Ruiz, Biosens. Bioelectron., 2005, 20, 2268-2375.

8 T. G. Park and A. S. Hoffman, J. Biomed. Mater. Res., 1990, 24, 21-38.

9 S. Nayak and L. A. Lyon, Angew. Chem., 2005, 117, 7862-7886.

10 R. Pelton and P. Chibante, Colloids Surf., 1986, 20, 247-256.

11 B. R. Saunders, Langmuir, 2004, 20, 3925-3932.

12 K. Kratz, A. Lapp, W. Eimer and T. Hellweg, Colloids Surf., A, 2002, 197, 55-67.

13 A. Burmistrova and R. von Klitzing, J. Mater. Chem., 2010, 20, 3502-3507.

14 S. Höfl, L. Zitzler, T. Hellweg, S. Herminghaus and F. Mugele, Polymer, 2007, 48, 245-254.
15 M. Karg, I. Pastoriza-Santos, B. Rodriguez-Gonzalez, R. von Klitzing, S. Wellert and T. Hellweg, Langmuir, 2008, 24, 6300-6306.

16 H. Kawaguchi, K. Fujimoto and Y. Mizuhara, Colloid Polym. Sci., 1992, 270, 53-57.

17 K. Fujimoto, Y. Mizuhara, N. Tamura and H. Kawaguchi, J. Intell. Mater. Syst. Struct., 1993, 4, 184-189.

18 M. Y. Arica, H. A. Öktem, Z. Öktem and S. A. Tuncel, Polym. Int., 1999, 48, 879-884.

19 N. Ortega, M. D. Busto and M. Perez-Mateos, Bioresour. Technol., 1998, 64, 105-111.

20 C. Johansson, P. Hansson and M. Malmsten, J. Phys. Chem. B, 2009, 113, 6183-6193.

21 C. Johansson, J. Gernandt, M. Bradley, B. Vincent and P. Hansson, J. Colloid Interface Sci., 2010, 347, 241-251.

22 N. Welsch, A. Wittemann and M. Ballauff, J. Phys. Chem. B, 2009, 113, 16039-16045.

23 G. Carrera and S. Riva, Angew. Chem., 2000, 112, 2312-2341.

24 K. M. Koeller and C.-H. Wong, Nature, 2001, 409, 232-240.

25 A. M. Klibanov, Nature, 2001, 409, 241-246.

26 H. Wack, A. Nellesen, K. Schwarze-Benning and G. Deerberg, J. Chem. Technol. Biotechnol., 2011, 86, 519.

27 G. S. Chauhan, S. Mahajan, K. M. Sddiqui and R. Gupta, J. Appl. Polym. Sci., 2004, 92, 3135.

28 N. Milasinovic, M. K. Krusica, Z. Knezevic-Jugovic and J. Filipovic, Int. J. Pharm., 2010, 383, 53-61.

29 H. Chen, L.-H. Liu, L.-S. Wang, C.-B. Ching, H.-W. Yu and Y.-Y. Yang, Adv. Funct. Mater., 2008, 18, 95-102.

30 Z. Meng, M. H. Smith and L. A. Lyon, Colloid Polym. Sci., 2009, 287, 277-285.

31 R. D. Nargessi and D. S. Smith, Methods Enzymol., 1986, 122, 67-72.

32 S. W. Provencher, Comput. Phys. Commun., 1982, 27, 213-227.

33 K. Kratz, T. Hellweg and W. Eimer, Colloids Surf., A, 2000, 170, 137-149.

34 K. Kratz, PhD thesis, University of Bielefeld, 1999.

35 J. Gao and Z. Hu, Langmuir, 2002, 18, 1360.

36 J. Uppenberg, M. T. Hansen, S. Patkar and T. A. Jones, Structure, 1994, 2, 293. 